\title{
Can Domain Theory Combined with the Resource-Based View Demonstrate the Missing Link in IT Value Creation
}

\author{
Bayer, Michael; Schorr, Franziska; Hvam, Lars
}

\section{Published in:}

Proceedings of the 2019 IEEE International Conference on Industrial Engineering and Engineering Management (IEEM)

Link to article, DOI:

10.1109/IEEM44572.2019.8978894

Publication date:

2019

Document Version

Peer reviewed version

Link back to DTU Orbit

Citation (APA):

Bayer, M., Schorr, F., \& Hvam, L. (2019). Can Domain Theory Combined with the Resource-Based View Demonstrate the Missing Link in IT Value Creation. In Proceedings of the 2019 IEEE International Conference on Industrial Engineering and Engineering Management (IEEM) IEEE.

https://doi.org/10.1109/IEEM44572.2019.8978894

\section{General rights}

Copyright and moral rights for the publications made accessible in the public portal are retained by the authors and/or other copyright owners and it is a condition of accessing publications that users recognise and abide by the legal requirements associated with these rights.

- Users may download and print one copy of any publication from the public portal for the purpose of private study or research.

- You may not further distribute the material or use it for any profit-making activity or commercial gain

- You may freely distribute the URL identifying the publication in the public portal 


\title{
Can Domain Theory Combined with the Resource-Based View Demonstrate the Missing Link in IT Value Creation?
}

\author{
M. Bayer ${ }^{1}$, F. Schorr ${ }^{1}$, L. Hvam ${ }^{1}$ \\ ${ }^{1}$ Department of Technology, Management and Economics, Technical University of Denmark, Lyngby, Denmark \\ (mbay@dtu.dk)
}

\begin{abstract}
The purpose of this paper is to apply the rationale of Domain Theory (DT) with the taxonomy of the Resource-Based View (RBV) to explain how information technology (IT) creates value. Based on literature, a conceptual model was developed, which is tested in a case study. Findings demonstrate that both theories combined are a novel way to describe the IT value creation. Particularly, breaking down the IT value construct into three domains, each described by functions and properties, demonstrates the IT value creation. Describing the IT value creation by functions and properties enables practitioners to both highlight the impact of IT and derive meaningful measurements to prove the value of IT. This research contributes to literature by applying the rationale of DT to describe the IT value creation.
\end{abstract}

Keywords - capability, Domain Theory, IT value creation, Resource-Based View, value of IT, wirk function

\section{INTRODUCTION}

Research on information technology business value (ITBV) has attracted researchers since over four decades. Initial findings showed no or even negative correlations between information technology (IT) and firm productivity (e.g., [1]-[3]). Later on, typically positive and significant associations between IT investments and both productivity and other operational performance measurements were reported (e.g., [4]-[7]). This has shifted the focus from whether IT creates value towards how and why IT creates value [8].

Most research on IT value creation lean on the Resource-Based View (RBV) (e.g., [9]-[12]), that views IT as a resource. IT combined with complementary resources creates value [9], [13], [14]. This infers that the RBV emphasizes under which conditions IT contributes towards value. However, the RBV falls short on means in order to describe the way IT creates value. This is coherent with the statement of Wiengarten et al. [9: 30], stating that "in-depth inquiry into ITBV is still needed."

The authors of this paper pioneer by applying the rationale of Domain Theory (DT) - an application of Systems Theory - in the IT value creation context. DT is commonly used for designing and developing physical products and describes a product by three domains, namely activity, organ, and part domain [15]. To develop a successful product, first the customer needs are identified in DT before successively the activity, organ, and part domain can be described [16]. This approach reversed can be regarded as the value chain of a product starting from an individual part of a product, via the organs to the activity the product is used for in order to solve customers' needs. Thus, the analytical break down structure of DT seems as a promising attempt to advance the field of IT value creation by combining the rationale of DT with the taxonomy of RBV.

\section{THEORETICAL BACKGROUND}

\section{A. Domain Theory}

DT is commonly used in the design area of physical products and describes a product on distinct domains. The domains allow representing a product on three system models (Fig. 1) [15], [16].

The first domain is the activity domain and outlines the way the product is used. The usage of the product is expressed by the technical activity. The user experience and the outcome of the technical activity should satisfy the user's needs and hence, being perceived as valuable [16], [17]. The product together with the other operators, such as user and surroundings, will transform the operands, such as material, information, energy, into a desired outcome. The desired outcome is the result of the use function of a product [16], [18]. The second domain, the so-called organ domain, views the product as one or more organs, each carrying a certain function. If stimuli act on the organ, it delivers in turn its wirk function [16], [18]. The term wirk function comes from the German Wirkungsweise and details how a product works or operates. Put differently, the wirk function describes the effects a product will deliver to solve one or more tasks in the technical activity [18]. The third domain, the part domain, specifies the elementary material elements of the organs and hence, of the product. A part's wirk function is described by the effect of the part in relation to its surroundings and other parts [16].

Consequently, DT enables to analytically disaggregate a product into three distinct systems, which are characterized by functions (i.e. use function, organ's wirk function, and part's wirk function) and properties Functions are the behavior of a system and thus have an effect on the properties of a system. Properties are the characteristics of a product and are related to the quality of a function, therefore such properties are also referred to function properties [18]. This means that the effects of a function, for example an organ's wirk function, are reflected on the properties of a product. 


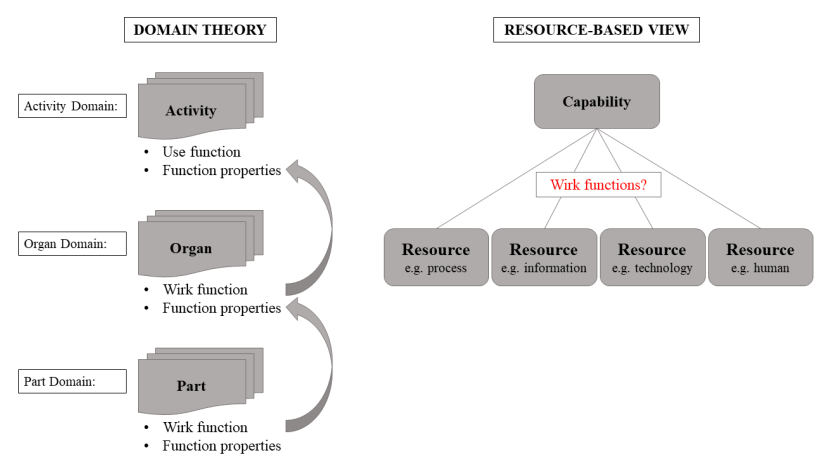

Fig. 1. Depiction of Domain Theory and Resource-Based View

The Moka Pot example by Andreasen, Howard, and Bruun [16] is used to exemplify DT with its domains, functions, and properties. The use function of the Moka Pot is to 'brew coffee'. 'Brewing coffee' can be characterized by function properties, such as the quality of coffee. The use function is the joint result of the technical activities (e.g. 'water and coffee powder filling', 'assembling the Moka Pot', and 'brewing the coffee'), the operators (e.g. user, stove, and the Moka Pot), and the operands (e.g. water and coffee powder). The Moka Pot's general wirk function is 'pressure transport'. This combined with the wirk function of the other operators, such as 'heat creation' from the stove, user's operations along the technical activities plus the operands produce coffee. The Moka Pot is a system of organs, where each organ has its own wirk function. The organs are for example, the 'boiler organ', 'transfer organ', 'brewer organ', and 'serving organ'. The wirk function of the 'brewer organ' is for example, 'brewing coffee'. The parts of the 'brewer organ' are two filters and the container for the coffee powder. The bottom filter's wirk function is to allow the water/stem enters the container, where the coffee powder is placed. The function properties of both the 'brewer organ' and the filter can be quality and reliability. Therefore, this example illustrates how DT can be applied in order to analytically describe a product by different domains and the contribution of each element to satisfy the user's need.

\section{B. Resource-Based View}

The RBV is a theoretical concept, which is commonly applied in the Strategic Management literature to explain competitive advantage of companies (e.g., [10], [13], [19]) and in the IT Management literature to describe the value creation of IT (e.g., [9]-[12]). Kohli and Grover [20] highlight that there is an important difference between creating differential value and use value. The former relates to competitive advantage, thus viewing individual resources and in combination as a source for differentiation, whereas the use value is associated with effects of using one or more resources combined. As this study aims to contribute to the value creation of IT, the use value will be the focal point.
The RBV by Barney [13] views an organization as a system of firm resources. Firm resources are all assets, which are controlled by an organization. These are for example capabilities, information, knowledge, technology, human, etc. Grant [19] differentiate firm resources into resources and capabilities. Capabilities are a mental construct of the configuration and integration of various resources with the aim to contribute towards firm goals (Fig. 1) [19], [21]. Thus, the RBV views resources as the constituents of capabilities and when these are deployed, they create value.

The research from Saldanha, Mithas and Krishnan [22] is used to demonstrate the RBV by an example. The capability in this case is the so-called analytical information processing capability, which is the capability of an organization to analyze business and customer data The use value of this capability is to better understand its business and market for decision-making [23]. The resources of the analytical information processing capability are business analytics technologies, business and customer data, staff, processes, etc. Those resources combined and deployed create value. This in turn means that IT by itself does not create value, only in combination with complementary resources [8], [9], [13], [14], [20], [24]. However, the RBV only describes the constituents of capabilities and under which conditions IT creates value. Nevertheless, the RBV does not explicitly express how the resources create value as DT achieves it through functions and function properties (Fig. 1).

\section{CONCEPTUAL MODEL}

Since DT is one way to describe the value chain of a product, this rationale of DT will be adopted as an attempt to describe the IT value creation. However, the taxonomy of the RBV will be incorporated in the conceptual model to be aligned with the taxonomy used in Strategic Management and IT Management literature.

The first domain, the activity domain in DT describes the use of the product by the technical activities. The general use of IT is to support or execute a process [25]. Thus, the activity domain and technical activity in DT is referred to process domain and business process, respectively. The use function in DT is the combination of technical activity, operands, and operators and translates into capability in RBV-terms. This translation is reasonable as a capability is defined as being the configuration of resources [19] and resources are all assets of a company, such as processes, information, technology, and humans [13].

The second domain in DT is the organ domain, where the product is divided into organs. Organs carry functions, so called wirk functions [16]. In Information Systems (IS) literature, IT or being precise IS are divided into modules (e.g., [26], [27]). Each module carry a certain function [28]. Thus, this domain is referred to module domain, where each module contains a wirk function. 


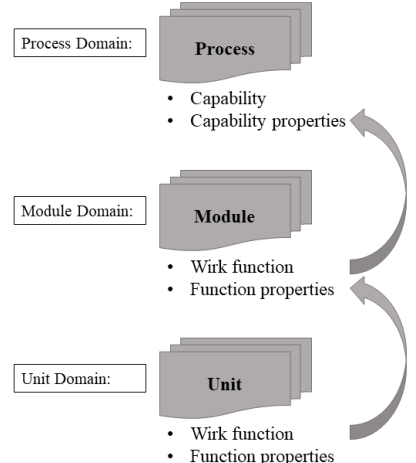

Fig. 2. Conceptual model to describe IT value creation

The third domain in DT describes the parts, which are needed to build the organs. Each part has a wirk function. Parts in DT can be associated with units in IS literature, where each unit has a function. Therefore, the third domain will be called units domain and is described by the unit's wirk function.

\section{METHODOLOGY}

Case research was applied to provide empirical arguments proving the applicability of the proposed conceptual model. This means that case research is used to test whether the conceptual model is applicable to describe IT value creation in a real-world setting [29]. The case study was conducted at one of the world's largest transportation and logistics service provider, which is called Transport Firm for confidentiality reasons. Transport Firm is considered representative in order to proof the applicability of the model, as it is a service provider with an IT-intense business model. Thus, IT plays a significant role in the value-creation.

The data were collected within the Road division, offering cargo transport by truck. The researchers selected the core capability, namely 'Route planning', out of the operating model of Road to provide proof-of-concept. The methods for data collection included observations, document reviews, and various meetings (TABLE 1).

\section{CASE STUDY}

The proposed conceptual model (Fig. 2) adopted the rationale of DT. The level of analysis of this paper is on process and capability level due to two reasons: (1) this paper does not aim to provide a model for IT/IS design and engineering and (2) the case company pursues a vendor-based IS-strategy, meaning that off-the-shelf IT/IS is sourced. Thus, the focus of IT/IS selection lays on module-level and how these module can support the given business process.

To assess the wirk function of the modules, which support one or more process steps, the business process for 'Route planning' needs to be illustrated (Fig. 3).
Hereafter, the modules and their wirk functions will be mapped into to the process map. In this case, the given process is supported by only one IS. Fig. 3 indicates that the business process 'Route planning' is supported by three IS modules, namely 'Order sequence planning', 'Vehicle planning', and 'Route planning'. The wirk functions of each module are 'Data processing', for example processing 'customer pick-up \& delivery data' to determine the sequence of collection.

TABLE I

SEQUENCE AND SOURCES OF DATA COLLECTION

\begin{tabular}{|c|c|}
\hline Sequence & Sources \\
\hline $\begin{array}{l}\text { Step 1: } \\
\text { Business } \\
\text { process } \\
\text { mapping }\end{array}$ & $\begin{array}{l}\text { - Internal document review on } \\
\text { business process } \\
\text { - Observations and meetings with } \\
\text { Freight forwarders and Enterprise } \\
\text { architects about business process } \\
\text { execution }\end{array}$ \\
\hline $\begin{array}{l}\text { Step 2: IS } \\
\text { module } \\
\text { mapping }\end{array}$ & $\begin{array}{l}\text { - Internal document review on IS } \\
\text { description and vendor description } \\
\text { - Meetings with Freight forwarders } \\
\text { and Enterprise architects about IT/IS } \\
\text { support }\end{array}$ \\
\hline $\begin{array}{l}\text { Step 3: Wirk } \\
\text { function } \\
\text { mapping }\end{array}$ & $\begin{array}{l}\text { - Meetings with Freight forwarders } \\
\text { and Enterprise architects to derive } \\
\text { the wirk function of both the modules } \\
\text { and the IS }\end{array}$ \\
\hline $\begin{array}{l}\text { Step 4: } \\
\text { Capability } \\
\text { properties } \\
\text { mapping }\end{array}$ & $\begin{array}{l}\text { - Meetings with Freight forwarders } \\
\text { and Enterprise architects to } \\
\text { determine the capability properties } \\
\text { of 'Route planning' }\end{array}$ \\
\hline
\end{tabular}

The capability of the business process depicted in Fig. 3, is 'Route planning'. The difference between capability and business process is that the former describes what a company does, whereas the latter expresses how a given capability is implemented. This distinction is important as 'Route planning' can be differently implemented per region or country. 'Route planning' produces as an outcome a 'Route plan' (Fig. 4). For that, the business process is executed in a combined manner by the Freight forwarder and IT. Whereas the Freight forwarder operates the IT system as well as executes the manual operations along the business process, the IT system determines the order sequence, vehicle availability, and route and distance (Fig. 3). IT/IS creates value due to its wirk function, in this case due to 'Data processing'. In other words, IT/IS processes data faster and better, especially with multiple constraints and parameters such as in determining the optimal route. This means that the value of IT are the performance gains due to IT/IS deployment. These performance gains can be assessed at the capability properties, which are for example speed, quality, accuracy, consistency, etc. Therefore, performance gains in speed and quality, meaning faster and better 'Route planning', are the value contribution due to IT/IS deployment, which is achieved by the wirk function 'Data processing' (Fig. 4). 


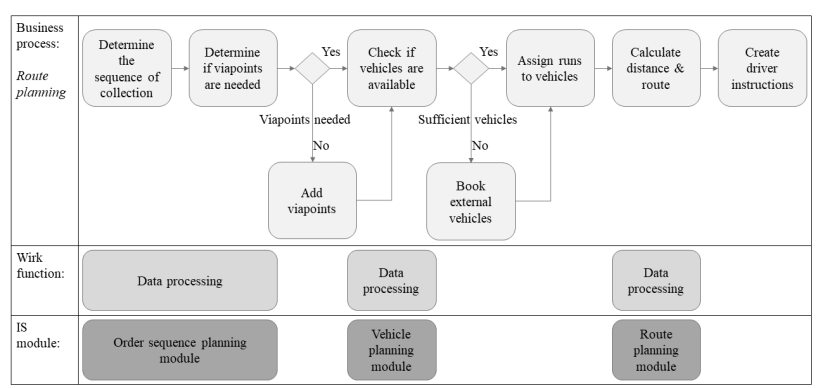

Fig. 3. Process map with IS modules and its wirk functions

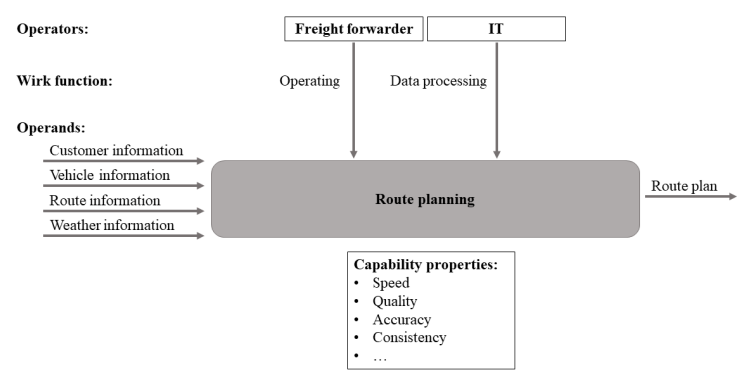

Fig. 4. Capability view

\section{DISCUSSION}

DT combined with RBV in form of the conceptual model is a novel way to describe the IT value creation. The conceptualized model applies the rationale of DT by describing each domain by its functions and properties [16]. Applying the rationale of DT is novel in two ways as the functions describe the value creation and the properties reflect the impact of IT. The actual impact produced by IT can be considered as the value of IT. For example, the wirk function of IT/IS in the given case study is 'Data processing'. The capability 'Route planning' can be characterized by the capability properties 'speed', 'quality', and so forth. Depending on the resource or operator mix, speed and quality of 'Route planning' differs. Assuming the given business process is completely manually executed; this will be ultimately reflected in a lower speed and quality of 'Route planning' in such an information-intense environment. Therefore, the IT/IS in this case contributes towards value through its wirk function 'Data processing' and consequently, affects the capability properties. Since IT can both process the sheer amount of data faster and determine consistently the optimal route, IT contributes towards 'increased speed' and 'better quality. Consequently, the increased speed and quality is regarded as the value of IT. Thus, this research contributes to the IT Management literature, in particular to IT value creation, by providing one way to describe the value creation of IT and hence, increases the understanding on how IT creates value [9], [20].

Furthermore, practitioners can use the proposed conceptual model to illustrate the IT contribution on business process and capability level. The use cases of the conceptual model are two folded: (1) to assess the current value-contribution of IT and (2) to apply a repeatable and rigid framework for business cases of future IT investments. Assessing the value contribution of IT can be done by successive understanding the wirk function of current or future IT and the impact of the wirk function on the capability properties. Since the conceptual model enables practitioners to describe how IT contributes towards value by their wirk function and its impact, KPIs contingent to functions and properties of IT can be derived. This objective is in line with the Chief Information Officer (CIO) of the case company as he expresses the need for meaningful measurements of the contribution of IT on overall firm performance. Therefore, this model can be a step forward to equip IT managers with an effective tool proving the contribution and value of IT.

This research gives rise for future research in three directions. First, future research is needed to validate the applicability of the proposed model. Second, through an extensive case study or a literature review additional wirk functions of IT could be determined. This is promising as the wirk function is an abstracted, generic characteristic of IT, which describes the value creation of IT. Determining additional wirk functions would contribute to an increased understanding of the different ways of value creation of IT. Third, since the wirk function of IT impacts capability properties, it could be interesting whether additional wirk functions might impact such properties differently. Such insights could give rise to meaningful, differential measurements for IT and would be in line with former research agendas (e.g., [30]-[32]).

\section{CONCLUSION}

This research is a pioneer by applying DT in the context of IT value creation. The authors conclude that DT adapted by the taxonomy of RBV is applicable to describe the IT value creation. In particular, it advances the current body of knowledge by describing the resource IT with its wirk function and the impact on the respective capability properties. In other words, the way IT contributes to value can be expressed by both its wirk function and its impact on the capability properties, which reflects the value of IT. Hence, DT is a novel way to express the IT value creation and therefore, enables practitioners to demonstrate the value of IT.

This research, however, does not claim to be flawless. The conceptual model needs further testing through additional case studies from various industries as this study only demonstrates the applicability of the model. Nevertheless, the authors of this paper hope that DT and its rationale applied in the IT value creation context will inspire future research. 


\section{REFERENCES}

[1] R. R. Panko, "Is Office Productivity Stagnant?," MIS Q., vol. 15, no. 2, pp. 191-203, 1991.

[2] G. P. Hackett, "Investment in Technology - The Service Sector Sinkhole?," Sloan Manage. Rev., vol. 31, no. 2, pp. 97-103, 1990.

[3] E. Brynjolfsson, "The Productivity Paradox of Information Technology," Commun. ACM, vol. 36, no. 12, pp. 66-77, 1993.

[4] T. Mukhopadhyay, S. Rajiv, and K. Srinivasan, "Information Technology Impact on Process Output and Quality," Manage. Sci., vol. 43, no. 12, pp. 16451659, 1997.

[5] E. Brynjolfsson and L. M. Hitt, "Beyond the Productivity Paradox," Commun. ACM, vol. 41, no. 8, pp. 49-55, 1998.

[6] J. Dedrick, V. Gurbaxani, and K. L. Kraemer, "Information Technology and Economic Performance: A Critical Review of the Empirical Evidence," ACM Comput. Surv., vol. 35, no. 1, pp. 1-28, 2003.

[7] T. A. Byrd, E. H. Thrasher, T. Lang, and N. W. Davidson, "A Process-Oriented Perspective of IS Success: Examining the Impact of IS on Operational Cost," Omega, vol. 34, no. 5, pp. 448-460, 2006.

[8] A. Neumeier, T. Wolf, G. Fridgen, H.-V. Müller, and C. Reith, "Natural and Design Science Perspective on the Business Value of IT," in Americas Conference on Information Systems, 2017, pp. 1-10.

[9] F. Wiengarten, P. Humphreys, G. Cao, and M. Mchugh, "Exploring the Important Role of Organizational Factors in IT Business Value: Taking a Contingency Perspective on the Resource-Based View," Int. J. Manag. Rev., vol. 15, no. 1, pp. 30-46, 2013.

[10] A. S. Bharadwaj, "A Resource-Based Perspective on Information Technology Capability and Firm Performance: An Empirical Investigation," MIS Q. Manag. Inf. Syst., vol. 24, no. 1, pp. 169-196, 2000.

[11] L. R. Suhardi, "Enterprise IT Value Engineering: A Proposed Method and Case Study," Int. Conf. Inf. Technol. Syst. Innov., no. November, pp. 195-200, 2014.

[12] A. Ordanini, "The Effects of Participation on B2B Exchanges: A Resource-Based View," Calif. Manage. Rev., vol. 47, no. 2, pp. 97-113, 2005.

[13] J. Barney, "Firm Resources and Sustained Competitive Advantage," J. Manage., vol. 17, no. 1, pp. 99-120, 1991.

[14] N. P. Melville, K. Kraemer, and V. Gurbaxani, "Review: Information Technology and Organizational Performance: An Integrative Model of IT Business Value," MIS Q. Manag. Inf. Syst., vol. 28, no. 2, pp. 283-322, 2004.

[15] M. M. Andreasen, "45 Years with Design Methodology," J. Eng. Des., vol. 22, no. 5, pp. 293 332, 2011.

[16] M. M. Andreasen, T. J. Howard, and H. P. L. Bruun, "Domain Theory, Its Models and Concepts," in $A n$ Anthology of Theories and Models of Design: Philosophy, Approaches and Empirical Explorations, A. Chakrabarti and L. T. M. Blessing, Eds. Springer London, 2014, pp. 173-196.

[17] C. Bowman and V. Ambrosini, "Value Creation Versus Value Capture: Towards a Coherent Definition of Value in Strategy," Br. J. Manag., vol. 11, no. 1, pp. 1-
15, 2000.

[18] T. J. Howard and M. M. Andreasen, "Mind-Sets of Functional Reasoning in Engineering Design," Artif. Intell. Eng. Des. Anal. Manuf., vol. 27, no. 3, pp. 233240, 2013.

[19] R. M. Grant, "The Resource-Based Theory of Competitive Advantage: Implications for Strategy Formulation," Calif. Manage. Rev., vol. 33, no. 3, pp. 114-135, 1991.

[20] R. Kohli and V. Grover, "Business Value of IT: An Essay on Expanding Research Directions to Keep up with the Times," J. Assoc. Inf. Syst., vol. 9, no. 1, pp. 23-39, 2008.

[21] R. Amit and P. J. H. Schoemaker, "Strategic Assets and Organizational Rent,” Strateg. Manag. J., vol. 14, pp. 33-46, 1993.

[22] T. J. V. Saldanha, S. Mithas, and M. S. Krishnan, "Leveraging Customer Involvement for Fueling Innovation: The Role of Relational and Analytical Information Processing Capabilities," MIS Q. Manag. Inf. Syst., vol. 41, no. 1, pp. 267-286, 2017.

[23] H. Chen, R. H. L. Chiang, and V. C. Storey, "Business Intelligence and Analytics: From Big Data to Big Impact," MIS Q. Manag. Inf. Syst., vol. 36, no. 4, pp. 1165-1188, 2012.

[24] R. I. Skinner, "The Value of Information Technology in Healthcare," Frontiers of Health Services Management, vol. 19, no. 3, pp. 3-15, 2003.

[25] L. Taxen and D. Svensson, "Towards an Alternative Foundation for Managing Product Life-Cycles in Turbulent Environments," Int. J. Prod. Dev., vol. 2, no. 1/2, pp. 24-46, 2005.

[26] S. Goutas, P. Soupos, and D. Christodoulakis, "A New Approach Towards an Object-Oriented Database System," Microprocess. Microprogramming, vol. 27, no. 1-5, pp. 127-132, 1989.

[27] G. Rakic, D. Milenkovic, S. Vujovic, T. Vujovic, and S. Jović, "Information System for e-GDP Based on Computational Intelligence Approach," Phys. A Stat. Mech. its Appl., vol. 513, pp. 418-423, 2019.

[28] S. Rice, “The power of MIS," In-plant Graph., vol. 57, no. 12, pp. 1-10, 2007.

[29] C. Voss, N. Tsikriktsis, and M. Frohlich, "Case Research in Operations Management," Int. J. Oper. Prod. Manag., vol. 22, no. 2, pp. 195-219, 2002.

[30] S. Aral and P. Weill, "IT Assets, Organizational Capabilities, and Firm Performance: How Resource Allocations and Organizational Differences Explain Performance Variation," Organ. Sci., vol. 18, no. 5, pp. 763-780, 2007.

[31] A. Rai, R. Patnayakuni, and N. Patnayakuni, "Technology Investment and Business Performance," Commun. ACM, vol. 40, no. 7, pp. 89-97, 1997.

[32] G. Schryen, "Revisiting IS Business Value Research: What We Already Know, What We Still Need to Know, and How We Can Get There," Eur. J. Inf. Syst., vol. 22, no. 2, pp. 139-169, 2013. 